This article is a report of search where the experiments are addressed and procedures involving discarded materials (they allowed the use of new techniques and new tools consequently), I am led to the construction of objects and sculptures and the relationship of this process in changing the paradigm the use of traditional materials in the world of visual arts. Use as background reference for the production of this work, relationships formed with objects of consumption that are permeados by the "vacuum" in our daily lives. Issues concerning the change of direction of discarded materials and their meanings in the context of that plastic visual production have been overhauled by Poiética methodology, which enabled the construction of dialogues of my work with that of other artists - whose production resulted from experiments, materials and objects of everyday use - as well as related theories, based on Jean Baudrillard, Michael Archer, William Tucker and Rolland Barthes.

Keywords: Objects/sculptures, discarded materials, daily life. 


\title{
Da tridimensionalidade para a transparência
}

\author{
Marco Aurélio \\ DAMASCENO
}

Este artigo é um relato de pesquisa onde são abordados as experiências e os procedimentos envolvendo materiais descartados (os mesmos possibilitaram o uso de novas técnicas e conseqüentemente novas ferramentas), que me levaram à construção de objetos e esculturas e a relação desse processo na mudança do paradigma da utilização dos materiais tradicionais no universo das Artes Visuais. Utilizo como fundo referencial para a produção deste trabalho, as relações constituídas com objetos de consumo que são permeados pelo "vazio" no nosso cotidiano. As questões relativas à mudança de rumo dos materiais descartados e seus significados no contexto dessa produção plástica visual foram analisadas de forma metodológica através da Poiética, que possibilitou a construção de diálogos da minha obra com a de outros artistas - em cujas produções resultaram de experimentações de materiais e objetos de uso cotidiano -, bem como com teorias afins, embasadas em Jean Baudrillard, Michael Archer, William Tucker e Rolland Barthes.

Palavras-chave: Objetos/esculturas, materiais descar- 


\section{Gênese: percurso pela poética dos materiais}

Da reflexão acerca do comportamento humano na sociedade de consumo, brotaram as inquietações que me conduziram à observação dos materiais os quais são descartados diariamente e classificados como "lixo". Foi em 1992 que, envolvido por um turbilhão de idéias, me veio, subitamente, o pensamento obsessivo de conceber e construir esculturas, utilizando o lixo. A partir desse momento, fiquei seduzido pela força poética e pelas possibilidades plásticas resultantes do uso de materiais que são descartados diariamente. Desde então, eles são uma constante como matéria-prima no meu trabalho artístico.

Andando pelas ruas da cidade de Salvador, voltei minha atenção para o tipo de relação que mantemos com objetos de consumo como produtos de plástico, latas, móveis usados, papéis e papelões, garrafas de vidro, embalagens de isopor e diversos refugos industriais que são poluentes. Após seu uso, esses materiais são execrados, abandonados e condenados à inutilidade para o consumo. A função de cada um deles como objeto já foi cumprida; agora são permeados pelo "vazio", ou seja, eles não passam de "descartáveis", transformados em "lixo". Com relação a esses materiais que compõem o universo dos objetos de circulação na sociedade de consumo, ponho-me diante dessa perspectiva relacional entre o sujeito e o uso destes, como produtos originados industrialmente até passarem a ser "lixo". Dando mais ênfase a essa relação, faço minhas as palavras do escritor Roquentin:

Os objetos foram sempre considerados um universo inerte e mudo, do qual dispomos a pretexto de que fomos nós que o produzimos. Mas, a meu ver, este mesmo universo tinha algo a dizer, algo que ultrapassava seu uso. Ele entrava no reino do signo, em que nada se passa de maneira tão simples, porque o signo é sempre o eclipse da coisa. O objeto designava, então, o mundo real, mas também sua ausência - e particularmente a ausência do sujeito. (ROQUENTIN apud BAUDRILLARD, 2001, p. 10-11).

Para a sociedade, tais materiais não tinham mais nenhum valor de uso, já não faziam parte das necessidades de consumo. "Parecia-me, no entanto, que havia uma possibilidade de 
as coisas circularem de outro modo" (BAUDRILLARD, 2001, p. 14). Com base nessa afirmativa, é interessante ressaltar que, se, perante a demanda da sociedade de consumo, muitos materiais são descartados diariamente por não terem mais valor de uso, sendo o lixo o seu destino final, nas Artes Visuais vem acontecendo o contrário, numa inversão de valores. Para alguns artistas, esses mesmos objetos podem readquirir valor quando transformados em arte. A História da Arte evidencia esse fato, ao registrar que diferentes artistas se apropriaram de diversos tipos de materiais, passando a usá-los como principal matéria na construção de objetos tridimensionais.

Essa busca de novos materiais no universo artístico teve início com as investigações de Pablo Picasso (1881-1973), o grande expoente do Cubismo, no período de 1912 a 1915, quando o artista realizou construções, utilizando pedaços de madeira, pregos e cordões. Dentre os trabalhos mais significativos, destaca-se "O instrumento Musical" (1914). A ordenação dos materiais nesse trabalho já determinou uma mudança radical no processo de construção da escultura, até então produzida com materiais tradicionais. "Nessa breve investida Picasso não apenas demonstrou o que a escultura poderia fazer sem as sanções históricas a temas e materiais, mas também deu-lhe uma liberdade potencial cujas implicações até hoje continuam sendo desenvolvidas" (TUCKER, 1999, p. 60).

Além de Picasso, outros artistas contribuíram para transformar as Artes Visuais, utilizando materiais não tradicionais e de uso cotidiano em suas produções, como é o caso de Vladimir Tatlin (1885-1953), que participou do Construtivismo. De acordo com os artistas desse movimento, "a idéia de que as Belas-Artes são superiores às chamadas artes práticas perdera a vitalidade" (SCHARF, 1974, p. 118). Tatlin, por exemplo, demonstrou conhecimento prático no uso irreverente dos materiais cotidianos, fato evidenciado no trabalho "Relevo de Canto" (1915). Segundo William Tucker,

a estética de Tatlin, sua "cultura de materiais", deriva da colagem cubista, do período que esteve com Picasso em Paris (1913). Os planos e as linhas curvas e retas, que representam os elementos da natureza-morta cubista, são transformados, nos relevos 
de Tatlin, de 1914-17, em formas 'funcionais', executadas com materiais reais. Chapas de aço e alumínio planas, enroladas ou cortadas em perfil; seções de madeira serradas, aplainadas, perfuradas; arame dobrado em curvas; cabos tencionados, além de vidro, barbante e outros materiais; todos organizados de maneira tensa e dinâmica em estruturas que parecem avançar para dentro do espaço do espectador. (TUCKER, 1999, p.121-123).

Outro artista que, de forma incontestável, conduziu ao extremo o seu desejo "de levar o objeto além do contexto em que ele poderia ser recebido e apreciado como arte" (TUCKER, 1999, p. 121) foi Marcel Duchamp (1887-1968), quando ele retirou simples objetos do uso cotidiano e levou-os para o trabalho artístico, denominando-os de ready-mades (o termo em inglês significa "já acabado"). Dentre esses objetos, destacam-se um urinol, na obra "Fonte", de 1917, cuja função foi modificada por ter o artista invertido sua posição, e um porta-garrafas, o qual, a partir do momento que foi contextualizado pelo artista como objeto de arte, teve esvaziada a sua função social de objeto de uso, passando a integrar-se na arte como uma obra para desfrute estético. Aqui no Brasil, um bom exemplo de produção plástica com materiais banalizados pela sociedade de consumo apresenta-se na obra do artista Arthur Bispo do Rosário. De acordo com Patrícia Burrowes,

O universo de Bispo comove pela força poética que extrai das banalidades. Coisas de uso cotidiano, comum; coisas triviais, quase vulgares, aparecem ali em sua seriedade, uma solene pobreza. Os materiais são rudes, toscos: a madeira vem sobretudo de caixas de feira e cabos de vassoura; o tecido vem de lençóis e cobertores do hospício; a linha azul é desfiada dos uniformes. Utilitários de plástico, copos, cestos, garrafas; canecas e talheres de metal; produtos de uso pessoal descartáveis, como canetas esferográficas, isqueiros, pentes, aparelhos de barbear; peças de carros e outras máquinas desfeitas; peças de vestuário, calçados; ferramentas; brinquedos de plástico; moedas; embalagens de alimentos, coisas dispensadas, sucata lixo. (BURROWES, 1999, p. 14).

Esses exemplos citados denotam as transformações ocorridas em conseqüência de investigações realizadas com base no uso de materiais simples nas Artes Visuais.

Dessa forma, incorporando o conceito de transversalida- 
de ao processo desta pesquisa, compactuamos com o conceito de "semiótica", segundo Pierce, de que "todo pensamento está nos signos", portanto "algo que está por algo por algum" (PIERCE apud FIDALGO, 1999, p. 9). Ou seja, na produção artística a situação significante desses materiais mudou, pois os materiais que foram jogados no lixo, considerados como desprovidos de sentido, passaram a ser (res)significados, a partir do momento em que foram transformados em arte pelos artistas citados. Estes inverteram, assim, a trajetória dos materiais quando os inseriram na produção artística, sinalizando o fato de que os materiais que antes não tinham mais sentido passaram a ocupar um lugar de valor na História como objeto de arte questionador das ações humanas.

No meu percurso como artista, o primeiro trabalho construído com materiais descartados foi o "Martelo de Deus". Trata-se de uma escultura constituída de vários pedaços de madeira descartados, e que antes fizeram parte do antigo teto da Escola de Belas Artes da Universidade Federal da Bahia (UFBA). Estes, juntamente com pedaços de cadeiras inutilizadas da escola, passaram a integrar a forma de um martelo gigante cujas partes foram aglomeradas com o uso de pregos. Um dado importante, na apresentação desse trabalho, que só foi percebido algum tempo após sua realização, quando já havia um certo distanciamento, foi a semelhança e sua relação direta com um objeto de uso cotidiano, fato que o aproxima da obra do artista Claes Oldenburg (1929), que construiu e expôs, na década de 60 , esculturas as quais tinham como referência objetos do cotidiano, e que se pareciam "demais com as coisas das quais derivavam" (TILLIM apud ARCHER, 2001, p. 14). Outro item de aproximação entre as esculturas de Oldenburg e o "Martelo de Deus" está no fato "de que o par de calças azuis incluído na mesma mostra teria servido num gigante" (ARCHER, 2001. p. 14) nesse trabalho do artista, percebendo-se, portanto, certa semelhança com o meu trabalho no que se refere à proporção.

No "Martelo de Deus", destacaram-se as dimensões (250 $\mathrm{cm} \times 550 \mathrm{~cm} \times 60 \mathrm{~cm}$ ); e os materiais, por terem adquirido uma nova significação com o reaproveitamento, já que deixaram de ser restos de um teto jogados num canto e não passaram a 
compor um martelo de origem industrial. Foi importante também, na instauração do trabalho, o fato de este ter sido exposto em um lugar que possibilitou o contato direto do espectador com a obra, já que, para transitar na galeria, o público obrigatoriamente tinha de passar de lado ou por baixo da escultura, pois esta estava localizada em uma área de acesso para a entrada e a saída da escola.

Após a construção do "Martelo de Deus", comecei a tomar consciência de que minha produção plástica visual estava voltada para um embate, um desafio estabelecido no contato direto com os materiais descartados. Então uma questão se colocou: como construir objetos tridimensionais com esses materiais me apropriando de suas formas e expressões sem descaracterizá-los? Partindo desse problema, foram germinando outras idéias, que convergiram para experimentações, usando como matéria-prima refugos de plástico.

O início dessa produção deu-se com a coleta e a seleção de refugos de diferentes tamanhos, formas e cores. A partir da manipulação, foram estabelecidos critérios para a escolha dos materiais, baseados nas suas qualidades inerentes: maleabilidade, opacidade, transparência, durabilidade e resistência ao tempo. Essas qualidades do plástico levaram-me a elegê-lo como um dos principais materiais a ser utilizados no trabalho. Após tais procedimentos, fui elaborando formas em que o desenho de cada vasilha plástica era aproveitado na composição tridimensional, na qual várias partes (diversos tipos de tampinhas e vasilhas plásticas) formavam um todo.

A princípio, a idéia foi construir esculturas compostas de vasilhas plásticas, buscando a organização desses materiais para gerar uma forma cuja composição e cuja fixação foram realizadas com perfurações e encaixes feitos de arame e com tiras de madeira, utilizados como sustentação. Ao mesmo tempo em que as tiras de madeira e os arames tinham a função de juntar e fixar um objeto ao outro, também criavam um ponto de apoio e de equilíbrio entre os mesmos, constituindo um esqueleto e um corpo no momento em que as vasilhas eram perfuradas pelos arames e pelas tiras de madeira. Com esses procedimentos, as vasilhas foram dispostas umas com as outras, unidas pelas 
suas bases superiores, inferiores e pelo centro, gerando pontos de apoio entre elas, e possibilitando, assim, a realização de esculturas e objetos.

$\mathrm{Na}$ constituição dessas esculturas, predominaram de forma aparente as cores fortes das vasilhas pelas suas derivações sintéticas e industriais. Quanto à veracidade da força das cores do plástico e do seu valor como material natural, Roland Barthes adverte, descrevendo sobre a impotência do plástico para atingir o mesmo triunfo de materiais naturais:

Mas aquilo que mais o trai [o plástico] é o som que produz, simultaneamente oco e plano. O ruído que produz derrota-o, assim como as suas cores, pois parece poder fixar apenas as mais químicas: do amarelo, do vermelho e do verde só conserva o estado agressivo, utilizando-as somente como um nome, capaz de ostentar apenas conceitos de cores. (BARTHES, 2001, p. 112).

O plástico surgiu como uma solução, com a industrialização de produtos, passando a substituir outras matérias, que têm suas origens na natureza; mas, como adverte "Barthes", as características que o plástico possui como material sintético - representadas pelo "som oco e plano" que produz e pela sua impossibilidade de atingir cores fortes e originais - colocam-no em desvantagem em relação aos materiais naturais. O plástico com suas qualidades inerentes passou a ser uma solução no universo dos materiais industrializados para o consumo. Mas será que o plástico não se tornou um problema para a sociedade contemporânea? Considerando tal questão, uma hipótese foi levantada durante a minha investigação plástica visual usando esse material. As embalagens plásticas utilizadas na produção de esculturas podem despertar o espectador para o "vazio" que nos habita em decorrência do acelerado consumismo na sociedade capitalista.

Assim, buscando atribuir um valor de cores fortes às vasiIhas, investi na construção de esculturas, usando as vasilhas de cores, numa oposição às vasilhas transparentes, que deixavam aparecer os arames e as tiras de madeira situados na sua parte interna. Partindo das combinações de cores fortes e da oposição de qualidades - de um lado a transparência e do outro a opacidade das vasilhas -, fui experimentando os materiais e 
ampliando os recursos técnicos para a execução e a resolução das figuras. Das garrafas plásticas foram aproveitadas as formas, de acordo com seus tamanhos e proporções, passando

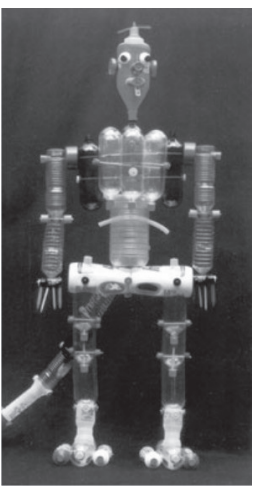

Figura 1 - "Adão na Idade do Plástico" (1993) estas a compor, numa bricolagem, novas formas de escultura ("Adão na Idade do Plásti$\left.\mathrm{CO}^{\prime \prime}\right)$.

Com a apropriação das garrafas plásticas e seu uso na construção das esculturas, ocorreram mudanças que foram alterando os resultados e direcionando o processo construtivo do trabalho para outros caminhos. Nesse estágio da pesquisa, estavam presentes indicativos de uma passagem, como uma porta que se abre tornando fatível vislumbrar outras possibilidades para a instauração do trabalho. Assim, a partir desse momento, aconteceram modificações nos procedimentos operativos para a construção das esculturas.

\section{“Trans/Aparências": um caminho para chegar ao vazio}

Após várias incursões realizando esse procedimento, cheguei à conclusão de que não mais satisfazia aproveitar essas formas, e passei a desconstruir recipientes plásticos, na intenção de suscitar outras possibilidades. Dentre os vários tipos de recipientes plásticos que tinha em mãos, destacaram-se os que possuíam a qualidade da transparência, passando a ser a transparência um dos principais elementos da pesquisa. Nessa fase do trabalho, a transparência estava representada por um revestimento de fitas de plástico, que recobria estruturas de arame, capaz de envolver e deixar ver não só o vazio interno da forma, mas, também, o espaço que a circundava. Além disso, esses materiais deixavam transparecer, com sua plasticidade, que no consumo há um abandono, um descaso, um não olhar para o outro.

Portanto, através da manipulação das garrafas plásticas transparentes e com um olhar reflexivo sobre os danos causa- 
dos no comportamento humano pela sociedade de consumo, comecei minha investigação na busca de instaurar uma produção tridimensional em que deixaria à mostra a vacuidade que o consumo nos imprime.

As vasilhas plásticas passaram a ser utilizadas como revesti-

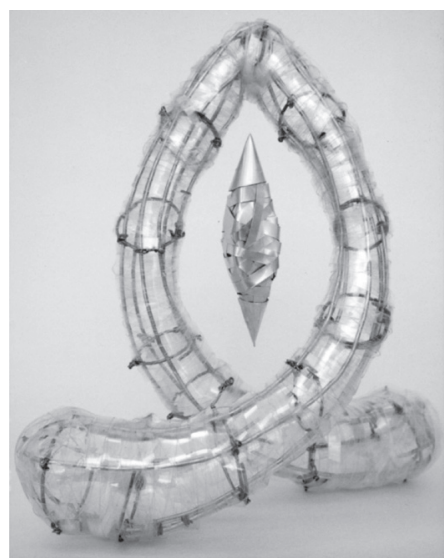

Figura 2 mento de estruturas de arame. Do procedimento construtivo anterior, foram eliminadas as tiras de madeira; a composição, que antes era realizada com garrafas coloridas, passou a ser feita com garrafas plásticas transparentes. Estas deixaram as suas formas de origem, para ser transformadas em fitas transparentes. Cortando a boca e o fundo da garrafa, teve início o processo de desconstrução; o corpo da vasilha foi utilizado, sendo recortado em espiral até formar uma fita de aproximadamente $4 \mathrm{~m}$ de

comprimento e $2 \mathrm{~cm}$ de largura. Para compor o revestimento de uma estrutura de arame, foram recortadas várias garrafas.

Continuando a confecção, as fitas plásticas foram sendo enroladas, envolvendo o corpo estrutural de arame, até conseguir realizar o encobrimento total da figura ("Trans/Aparências") [fig. 2]; essa operação assemelha-se a uma mumificação, já que nenhuma parte da forma deixa de ser recoberta. Após essa etapa, estando a forma toda revestida de plásticos transparentes, teve início o acabamento final, feito com alumínio, em forma de plano, que foi recortado de latas; os planos de alumínio foram transformados em cones que passaram a integrar o objeto nas suas extremidades. O alumínio, que compõe o objeto, é um elemento que contém em si qualidades opostas ao plástico, pois não se deixa atravessar pela luz, possui a capacidade de absorver a temperatura ambiente e reflete os raios luminosos; nesse trabalho, o alumínio funciona como receptor de energia e transmissor desta para a parte interna do objeto. Todas as formas esculturais geradas e realizadas durante o processo citado possuem características comuns, ou seja, elas se 
assemelham a formas orgânicas unicelulares. De maneira subjetiva, associei essas formas à natureza, com seus quatro elementos. Imaginei que as extremidades pontiagudas superiores e inferiores de cada peça teriam uma relação de fluxo com os elementos: água, terra, fogo e ar. Partindo desse princípio, os materiais, antes considerados como poluentes do meio ambiente, foram transformados em objetos que restabelecem um ciclo na natureza, dinamizado pela sua utilização no fazer artístico. Esses objetos, por terem adquirido a capacidade de transitar entre a aparência do real e a do imaginário, foram denominados de "Trans/Aparências" e integraram uma exposição, parte da pesquisa, que foi realizada na Galeria da Aliança Francesa.

Nessa galeria, após ultrapassar o portal de entrada, olhando para o seu lado esquerdo, o espectador deparava-se com o seguinte poema:

\section{Atravessar o mundo da imagem (Ismália, torre, mar). Estourar o cristalino Ali \\ Se fizéssemos a possibilidade: Sendo dados: \\ A arte ininterrupta de olhar: Trans/Aparências: Espelho do Castelo da pureza.}

(Para Marco, de Ayrson Herclito e Beto Herclito, 21/2/2002)

ESCULTURA - "TRANS/APARÊNCIAS" (2002) A exposição foi montada em duas salas; na sala principal, ficaram expostas cinco esculturas; o posicionamento de cada uma evidenciava a unidade do conjunto e, ao mesmo tempo, sugeria um diálogo entre elas e o espectador. Outro aspecto importante na disposição das esculturas foi o fato de elas terem permanecido suspensas por fios de nylon fixados no teto da galeria. Essa montagem possibilitou ao espectador uma visão de leveza e flutuação das esculturas no espaço vazio, fortalecendo também suas características inerentes, inclusive a de se assemelhar a seres vivos. Em outra sala menor, foi montada uma instala- 
ção composta de dois objetos colocados sobre dois tablados brancos; tais objetos, feitos dos mesmos materiais das esculturas, estavam guardados em caixas transparentes de acrílico. Além dos objetos citados, foram colocadas, na parede interna em frente à porta que dá acesso à sala, cinco transparências dos projetos das esculturas; eram desenhos que continham, em suas estruturas lineares, indicações textuais demonstrando as funções e as relações espaciais das esculturas com os quatro elementos.

No decorrer das operações que foram descritas, tive como principal objetivo desenvolver peças tridimensionais que especificamente apresentassem a qualidade de transparência.

\section{Referências}

ARCHER, Michael. Arte contemporânea, uma história concisa. São Paulo: Martins Fontes, 2001.

ARNHEIM, Rudolf. Arte e percepção visual: uma psicologia da visão criadora. São Paulo: Pioneira,1986.

BARTHES, Roland. A câmara clara. Rio de Janeiro: Nova Fronteira, 1984. Mitologias. Rio de Janeiro: Bertrand Brasil, 2001.

BAUDRILLARD, Jean. O sistema dos objetos: São Paulo: Perspectiva, 1989. A sociedade de consumo. Lisboa: Edições 70, 1995.

A ilusão vital. Rio de Janeiro: Civilização Brasileira, 2001. Senhas. Rio de Janeiro: DIFEL, 2001.

BURROWES, Patrícia. O universo segundo Arthur Bispo do Rosário. Rio de Janeiro: Editora FGV, 1990.

DERRIDA, Jaques. O animal que logo sou. São Paulo: Editora UNESP, 2002.

FIDALGO, Antonio. Da semiótica e seu objecto. Belo Horizonte: Universidade da Beira Interior: Disponível em: < www.bocc.ubi.pt>. Acesso em: 01 de junho de 2003.

HOUAISS, Antonio. Dicionário da língua portuguesa. Rio de Janeiro: Editora Objetiva, 2001.

TUCKER, William. A linguagem da escultura. São Paulo: Cosac \& Naify, 1999. 
VISUALIDADES. REVISTA DO PROGRAMA DEMESTRADO EM CULTURA VISUAL - FAVIUFG 
Da tridimensionalidade para a transparência

\section{MARCO AURÉLIO DAMASCENO}

Mestre em Artes Visuais pela Escola de Belas Artes da UFBA, Professor Assistente Nível I do Departamento de Artes Visuais da Universidade Federal da Paraiba, participou de mostras individuais e coletivas no Brasil e no exterior, prêmios e obras em acervos públicos. 